\title{
Anti-Hypercholesterolemic and Hepatoprotective Effect of Aqueous Seed Extract of Carica Papaya in Rats Fed with Thermoxidized Palm Oil Diet
}

\author{
EBO, Obehi Emmanuella ${ }^{1 *}$, IGHODARO, Chinyem Nkemjika² ${ }^{2}$ SILAS, Wisdom John ${ }^{3}$, ALOAMAKA, \\ Ogechukwu Emmanuel $^{4}$, CHIME, Anthonia Odinika ${ }^{5}$
}

1-4 Department of Physiology, College of Basic Medical Sciences, University of Benin, Nigeria.

${ }^{5}$ Department of Plant Biology and Biotechnology, Faculty of Life Science, University of Benin.

*Corresponding Author

EBO, Obehi Emmanuella

Department of Physiology, College of Basic Medical Sciences

University of Benin, Benin City

Nigeria

Tel:07035522957

Email: emmanuella.okojie@uniben.edu

Received:21 September 2020; | Revised:31 October 2020; | Accepted:16 March 2021

\section{Abstract}

The use of plants by man for the treatment of diseases has long been in practice. This study sought to investigate whether or not the aqueous seed extract of Carica papaya will ameliorate the injurious effect of thermoxidized palm oil. Fifty (50) rats, consisting of males and females were divided into five groups. The rats in group 1 served as the control, they were fed with rat chow and water ad libitum. Group 2 rats were fed with fresh palm oil diet (FPO). Group 3 rats were fed with thermoxized palm oil (TPO). Group 4 rats were fed with fresh palm oil diet and $500 \mathrm{mg} / \mathrm{kg}$ body weight aqueous seed extract of Carica papaya. Group 5 rats were fed with thermoxidized diet and aqueous seed extract of Carica papaya. Each of the palm oil diet contained $15 \%(\mathrm{w} / \mathrm{w})$ thermoxidized or fresh palm oil. At the end of 28 days administration, blood samples were collected for the analysis of lipid profile and some liver function enzymes. The results showed that HDL was significantly $(\mathrm{P}<0.05)$ increased in all the test samples except TPO, while LDL followed a reverse trend. Total cholesterol concentration showed a significant increase $(\mathrm{P}<0.05)$ in all the test groups with the exception of the TPO group, which decreased significantly $(\mathrm{P}<0.05)$ when compared with the control. The Serum Alkaline Phosphatase (ALP), Aspartate Amino Transferase (AST) and Alanine Amino Transferase $(\mathrm{ALT})$ were significantly $(\mathrm{P}<0.05)$ reduced in all the test samples except TPO which was significantly $(\mathrm{P}<0.05)$ increased. Serum gamma glutamyl transpeptidase (GGT) showed decrease in all the test samples except TPO which was significantly $(\mathrm{P}<0.05)$ slightly increased. The results indicate that consumption of thermally oxidized palm oil diets had deleterious effects on biochemical indices in rats. Also, the seed extract of Carica papaya has anti-hypercholesterolemic effect. The serum enzyme levels also show that the liver tissue integrity was stabilized by the addition of Carica papaya seed extract to thermoxidized palm oil diet hence its hepatoprotective activity.

Keywords: Anti-hypercholesterolemic, Hepatoprotective, Carica papaya, Thermoxidized palm oil 


\section{Introduction}

For decades, medicinal plants have been used for different purposes and today almost every part of the world uses them for the treatment of different diseases ${ }^{[1]}$. In Nigeria, these medicinal plants form a vital component of the natural wealth of the country ${ }^{[2]}$. However, attention has been given to the medicinal value of herb remedies for safety, efficacy and economy ${ }^{[3]}$. Traditionally, medicines from plant sources of wide variety have been used effectively in the treatment of hypercholesterolemia. Hypercholesterolemia is predicted to be the main cause of death worldwide; it is a major risk factor for coronary artery disease and thus stroke and myocardial infarction ${ }^{[4]}$. Carica papaya (family Caricaceae), commonly known for its food and nutritional values throughout the world, is a shrub, tropical tree which is a native of the tropics of the Americans (Southern Mexico and Costa Rica) but now widely cultivated in other tropical regions of the world such as Australia, Hawaii, Philippines, Sri Lanka, South Africa, India and Nigeria ${ }^{[5]}$. It is known for its tasty, edible and melon-like fruit which is available throughout the year ${ }^{[6]}$. In some parts of Nigeria and Islands of the West Indies like Sri Lankan, it is known as pawpaw, in Cuba, it is often called fruta bomba and lechoza in Venezuela, Puerto Rico, Philippines and Dominican Republic. Erstwhile, a number of medicinal properties have being ascribed to various parts of this tree mostly the root, leaves, roots, bark, stem, fruits, flowers, seed, gum and seed oil. Imaga et al., ${ }^{[7]}$, reported that papaya as a good source of nutrient, also possess some Phytochemicals such as betacryptoxanthin and benzylisothiocyanates. Furthermore, Phytochemical analyses also reveals the presence of polysaccharides, vitamins, minerals, enzymes (papain and chymopapain), proteins, fats and oils, tannins, carpaine, nicotine, terpenes, anthraquinones, anthocyanosides, terpenoids, alkaloids, flavonoids, glycosides, saponins and steroids ${ }^{[8-10]}$. The Crude seed extract was reported to reduce cholesterol in the liver and kidney ${ }^{[10]}$. A study conducted by Adeneye and Olagunju [8] investigated the hypoglycemic and cardioprotective effects of the aqueous seed extract of Carica papaya Linn (CPE) in normal male Wistar rats for 30 days.
On the other hand, Palm oil is widely used for cooking in Africa. It is derived from the fruit of Elaesis guineensis. It contains a high proportion of saturated palmitic acid, as well as considerable quantities of oleic and linoleic acids, which gives it a higher unsaturated content than coconut and palm kernel oil (the minor oil obtained from palm oil) ${ }^{[11]}$. It is increasingly used in the commercial food industry in other parts of the world due to its lower cost and the high oxidative stability (saturation) of the refined product when used for frying ${ }^{[12]}$. It can be consumed in the fresh and thermally oxidized forms. It is in the fresh form, when obtained from the pulp of the palm fruits by squeezing and boiling at low temperature to remove debris and when the fresh form is subjected to heating at high temperatures and at different time intervals, it is thermally oxidized. Generally, palm oil is thermally oxidized to increase its palatability and this is a usual practice in most homes. However, ingestion of thermally oxidized palm oil possesses potential dangers to the physiological and biochemical functions of the body. Oxidized palm oil induces adverse effect on plasma lipid profile, free fatty acids, phospholipids and cerebrosides. Carotenoids present in palm oil acts as biological antioxidants. Antioxidants are said to be a special group of nutritional supplements that scavenge free radicals ${ }^{[13-14]}$, thus protecting the cells from damage caused by a free radical. Nevertheless, Carica papaya has been associated with several attributes from rich Phytochemicals constituent to acting as an antioxidant as well as other health enhancing properties.

Therefore, this study sought to investigate whether or not the aqueous seed extract of Carica papaya will ameliorate the injurious effect of thermoxidized palm oil.

\section{Materials and Methods}

\subsection{Preparation of Aqueous Extract of Carica papaya seed}

Twenty (20) matured, unripe fruits of Carica papaya were purchased from a cultivated Pawpaw Plantation at Ovbiogie town, Ovia North-East, Benin City, Nigeria, on the 2nd week of August, 2019. Identification was done by Mr. Sunny Nweke of Pharmacognosy Department, Faculty of 
Pharmacy, University of Benin, Nigeria. The fruits were cut into longitudinal halves and the wet seeds were separated out. These were then gently but thoroughly rinsed in tap water and air-dried for 2 weeks. The dried seeds were pulverized into a fine powder by using an electrical grinding machine in the department of Pharmacognosy, University of Benin. The powdered sample was stored in an air tight container till when needed for analysis. The Carica papaya seeds powder was then pounded in a small laboratory mortar. $250 \mathrm{~g}$ of the powdered Carica papaya seed was mixed in $500 \mathrm{ml}$ of distilled water. After thorough mixing, the mixture was filtered using Whatman filter paper. The filtrate formed the stock solutions of Carica papaya seed aqueous extracts.

Doses of $500 \mathrm{mg} / \mathrm{kg}$ body weight were prepared from the stock solution, using calculation for the required doses for oral route.

Mean Weight of the rats per group $=\chi_{0}$; Amount of stock solution $=\chi_{1}$; Dose for Xrat $=$ $\chi_{1} / 1000 \mathrm{~g} \mathrm{X} \chi_{0}$

\subsection{Experimental Animals and Design}

Fifty (50) healthy albino Wistar rats consisting of 25 males and 25 females weighing about (200$250 \mathrm{~g}$ ) were used for the study. They were bred in the Animal House of the Department of Pharmacology and Toxicology, Faculty of Pharmacy, University of Benin. All rats were left to acclimatize for 2 weeks. The rats were randomly assigned into five (5) groups of ten rats each. Group 1 rats served as the control group and were fed with normal feed and water. Group 2 rats were fed with fresh palm oil diet (diet I). Group 3 rats were fed with thermoxized palm oil (diet II).Group 4 rats were fed with fresh palm oil diet and $500 \mathrm{mg} / \mathrm{kg}$ body weight aqueous seed extract of Carica papaya. Group 5 rats were fed with thermoxidized diet and aqueous seed extract of Carica papaya. All administration was done orally for 28days using orogastric tubes. The animals were housed in wired cages at atmospheric temperature $(28 \pm 20 \mathrm{C})$ and had $12 \mathrm{hrs}$ light-dark cycle. They were fed and allowed access to water ad libitum. Good hygiene was maintained by constant cleaning and removal of faeces and spilled feed from cages daily. All experiments on the animals were carried out in accordance with the NIH guide for the care and use of laboratory animals (NIH publication No. 8023, revised 2002) and ethical approval of the study was done by the Faculty of Pharmacy Ethics Committee, University of Benin, Edo State, Nigeria.

\subsection{Sources and Preparation of Thermoxidized Palm Oil}

The sample was prepared according to the method of ${ }^{[15]}$. Twenty (20) litres of fresh palm oil was purchased from Oluku market, in Ovia NorthEast Local Government of Edo State, Nigeria. The oil was divided into two equal parts. One part was used in its fresh form and the other was thermally oxidized. Fresh palm oil was heated at $1500 \mathrm{C}$ in a stainless steel pot intermittently for five times with each lasting twenty minutes. At the end of each heating session, the oil was allowed to cool for five hours.

\subsection{Formulation of Diet}

Fifteen gram (15g) of the cooled thermoxidized palm oil was mixed with eighty-five grams of rats feed and was designated test diet II (TPO) while Fifteen grams of fresh palm oil was mixed with eighty-five grams rat feed and was designated as test diet I (FPO) (Since the level of palm oil in most West African dishes is about $15 \%$ ${ }^{[11]}$. The diets were stored in black containers at $40{ }^{\circ} \mathrm{C}$ to prevent further oxidation of the oil component.

\subsection{Assay kits}

Randox assay kits were used for the assay of Alkaline Phosphatase (ALP), Aspartate Amino Transaminase (AST), Alanine Amino Transferase (ALT) and Gamma Amino Transferase (GGT), Cholesterol, HDL-cholesterol and Triglyceride, following the manufacturer' instructions. While LDL was assayed using the direct immuneInhibition method. Automated analyzer (902) machine was used. All assay kits were purchased from Pyrex Scientific Industries, Benin, Edo state, Nigeria. All reagents used in this study were of high quality and analytical grade.

Clinical observations were also made once a day for Mortality, Moribund and ill health or reaction to treatment such as changes on skin and fur, eyes and mucus membrane, behavioral pattern, diarrhea and coma. Also, individual rats were 
weighed before the commencement of the experiment and the final body weight was recorded prior to the scheduled necropsy.

\subsection{Collection of Blood and Serum Samples}

After twenty-eight (28) days of feeding, the rats were subjected to an overnight fast, and were anaesthetized with chloroform/ether mixture in ratio 1:1. Their thoracic cavities were opened and blood withdrawn by cardiac puncture using a $5 \mathrm{ml}$ syringe into properly labeled non-heparinized tubes. The sample bottles were allowed to stand for $1 \mathrm{hr}$ after which they were spun at a speed of 3000 revolutions per minutes (rpm) for five minutes using MSE centrifuge (England). At the end of the spinning process, the sample bottles were removed from the centrifuge and the uppermost strawcoloured serum was drawn out using syringes. The serum samples were emptied into a different sample bottles properly labelled for the determination of serum lipid profile and liver function enzymes.

\subsection{Statistical analysis}

All data are expressed as Mean \pm Standard error of mean (Mean \pm S.E.M). The data obtained was analyzed using the One Way Analysis of Variance and Student t-test was used for multiple comparisons. (Graph pad prism 8.0 statistical package was used). They were presented in tables and figures. The $(\mathrm{P}<0.05)$ was accepted as significant.

\section{Results}

The results showed that there was significant reduction in Serum ALT, AST and ALP $(\mathrm{P}<0.05)$ in all test group except Group 3 (TPO), which was significantly increased when compared with control $(84.04 \pm 0.23,68.23 \pm 0.25,64.35 \pm 0.41,40.23$ \pm 0.32) $(\mathrm{P}<0.05)$ as shown in Table 1 below. Similarly, the results of serum GGT showed a decrease in the test groups which was statistically insignificant $(\mathrm{P}>0.05)$. Still more there was a slight significant increase when compared with the control $(\mathrm{P}<0.05)$.

Furthermore, the result showed the effect of $\mathrm{FPO}, \mathrm{TPO}, \mathrm{FPO}+\mathrm{CP}$ and $\mathrm{TPO}+\mathrm{CP}$ on serum lipid profile of Wistar albino rats. Total cholesterol concentration showed a significant increase $(\mathrm{P}<0.05)$ in all the test groups with the exception of the TPO group, which decreased significantly $(2.30 \pm 0.31$, $3.25 \pm 0.28,2.00 \pm 0.01,2.75 \pm 0.33,2.40 \pm 0.05)$ $(\mathrm{P}<0.05)$ when compared with the control, as shown in Figure 1 below. Also, the Triglyceride concentration showed a significant increase in all the test groups when compared with the control $(2.55 \pm 0.20,3.25 \pm 0.18,3.48 \pm 0.22,2.83 \pm$ $0.02,4.16 \pm 0.14)(\mathrm{P}<0.05)$, as shown in Figure 1. With HDL-Cholesterol, there was also a significant increase $(\mathrm{P}<0.05)$ in all the test groups, except for the TPO group, which showed a significant decrease when compared with the control (2.03 \pm $0.30,2.54 \pm 0.21,1.24 \pm 0.48,3.65 \pm 0.02,3.20 \pm$ 0.15 ) as shown in Figure 1. The results of LDLcholesterol showed a significant decrease in all the test groups $(\mathrm{P}<0.05)$ except for TPO group which showed a significant increase when compared with the control $(3.25 \pm 0.31,1.52 \pm 0.28,5.23 \pm 0.16$, $1.31 \pm 0.42,1.02 \pm 0.46)(\mathrm{P}<0.05)$, as seen in Figure 1 below.

Table 1: Effect of FPO, TPO, FPO + CP and TPO + CP on some liver enzymes of Wistar albino rats

\begin{tabular}{lllll}
\hline PARAMETERS & ALT (U/L) & AST (U/L) & ALP (U/L) & GGT (U/L) \\
\hline GROUP 1 & $52.40 \pm 0.01$ & $32.34 \pm 0.32$ & $43.04 \pm 0.43$ & $30.43 \pm 0.15$ \\
GROUP 2 & $30.54 \pm 0.35^{*}$ & $21.37 \pm 0.16^{*}$ & $32.40 \pm 0.27^{*}$ & $18.01 \pm 0.36$ \\
GROUP 3 & $84.04 \pm 0.23^{*}$ & $68.23 \pm 0.25^{*}$ & $64.35 \pm 0.41^{*}$ & $40.23 \pm 0.32^{*}$ \\
GROUP 4 & $43.40 \pm 0.34$ & $45.10 \pm 0.42$ & $18.45 \pm 0.15^{*}$ & $21.32 \pm 0.26$ \\
GROUP 5 & $32.34 \pm 0.04^{*}$ & $30.58 \pm 0.57$ & $28.32 \pm 0.22$ & $28.41 \pm 0.12$ \\
\hline
\end{tabular}

Results are expressed in mean \pm SEM $(n=5) *$ significant at $\mathrm{P}<0.05$ compared with the control. ALT, alanine aminotransferase; AST, aspartate aminotransferase; ALP, alkaline phosphatase; GGT, gamma aminotransferase; FPO, fresh palm oil (diet); TPO, thermoxidized palm oil (diet) FPO $+\mathrm{CP}$, fresh palm oil + Carica papaya; $\mathrm{TPO}+\mathrm{CP}$, thermoxidized palm oil + Carica papaya 


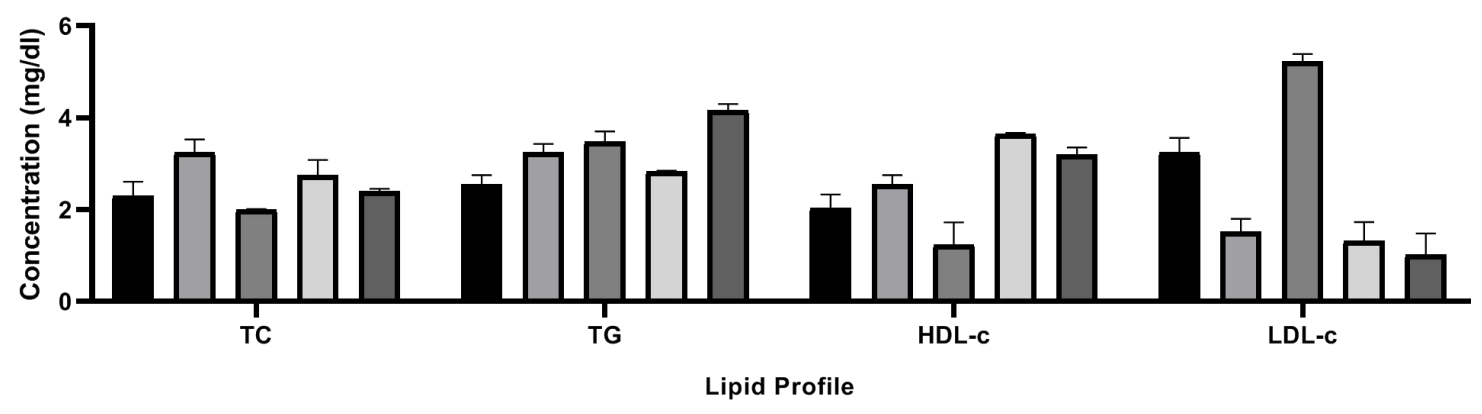

Figure 1: Effect of FPO, TPO, FPO + CP and TPO + CP on serum lipid profile of Wistar albino rats FPO, fresh palm oil (diet); TPO, thermoxidized palm oil (diet) FPO + CP, fresh palm oil + Carica papaya; TPO + CP, thermoxidized palm oil + Carica papaya

\section{Discussion}

This study was conducted in rat's model to ascertain the anti-hypercholesterolemic and hepatoprotective effect of Carica papaya on rats fed with thermoxidized palm oil diet. Measurement of major lipids like cholesterol, triglycerides, highdensity lipoprotein cholesterol, low-density lipoprotein cholesterol and very low-density lipoprotein cholesterol has given useful information about the functioning of the heart [16]. High concentrations of all lipids except the high-density lipoprotein cholesterol were associated with an increased risk of artherosclerosis. The results of the present study on assessment of the lipid profile revealed that there was a significant increase in the Total cholesterol in all the test groups except TPO. This result is in agreement with the report by Thomas [17], who provided details concerning reducing plasma cholesterol concentration in animals fed oxidized oil. Serum cholesterol concentration is a risk factor for coronary heart disease. The increase in Cholesterol concentration in the test groups may have been as a result of formation of adrenocortical and sex hormones.

Also, there was a significant increase in TG of all the test groups including TPO. Rats which consumed thermally oxidized oil (TPO) had significantly higher concentration of triglyceride. Ingestion of excess amounts of fat contributes to coronary heart diseases and even other chronic diseases ${ }^{[18]}$.

Furthermore, there was significant increase in the HDL-C of all the test groups but a reverse in the case of TPO and a significant decrease in LDL-C in all the test groups but a reverse effect by TPO. The presence of Phytochemicals in Carica papaya such as flavonoids and phenolic acids may have mopped up the free radicals produced by TPO, thereby restoring an improved HDL-C level as seen in TPO+ CP. The observed LDL-Cholesterol lowering effect, especially in the test groups fed with Carica papaya, could be associated to the effect of saponins. Saponins are known to be antinutritional factors which reduce the uptake of certain nutrition especially cholesterol at the gut through intraluminal physiochemical interactions. Erstwhile, studies have reported saponins to have hypocholesterolic effect ${ }^{[19]}$. However, the apparent significant decrease in the total cholesterol and HDL-c with a concomitant significant increase in the LDL-c level in TPO indicates a significant shift towards formation of bad cholesterol (LDL-c). LDL-c makes up most of the body's cholesterol and 
high levels of its raises the risk of Heart disease and stroke ${ }^{[16]}$. Nevertheless, with the addition of Carica papaya seed extract, a reversal in this shift was thereby stabilizing the production of good cholesterol (HDL-c). HDL-c absorbs cholesterol and carries it back to the liver, where it is flushed from the body. High level of HDL-c is beneficial to health since it reduces the risk of coronary heart disease (CHD) ${ }^{[20]}$. The observed significance $(\mathrm{P}<0.05) \quad$ increase in HDL-Cholesterol concentration upon the administration of the extract indicates that the extract doses have HDLCholesterol boosting effect.

Similarly, investigations on some liver function enzymes suggest that thermoxidized palm oil has a deleterious effect on the liver when compared with the fresh palm oil. Osim et al., [20], reported that the consumption of thermoxidized palm oil diets caused liver damage. However, it was observed that the addition of Carica papaya reversed this effect as seen in the decreased serum GGT levels of TPO+ CP. The serum ALP, AST, ALT and GGT activities of the group fed thermally oxidized palm oil diets increased significantly $(\mathrm{P}<0.05)$ when compared with the control (Table 1). The increase in ALP appears to be lipid-dependent, because ingestion of fat leads to an increase in ALP synthesis by rat intestinal mucosa ${ }^{[21]}$. Also, the observed increase in ALP, AST and ALT activities might be due to alterations in the membrane architecture of the cells of the liver of rats fed thermally oxidized palm oil diets, hence an effect on the liver integrity. Therefore, the increase in liver function enzymes ALT, AST, ALP as well as GGT is suggestive of liver disease including hepatic necrosis, severe hepatocellular injury and cholestasis ${ }^{[2]}$.

\section{Conclusion}

From the presented results, it can be concluded that Carica papaya seed extract possesses antihypercholesterolemic effect. It also exercises hepatoprotection due to the presence of Phytochemicals that were able to mop up free radicals produced from the thermoxidized palm oil. Therefore, the seed extract of Carica papaya can serve palliative measures in cases of possible toxicity from consumption of thermoxidized oil diets. The consumption of thermally oxidized palm oil diets had a deleterious effect on biochemical indices in the rats.

\section{Conflict of interest}

The authors declare no conflict of interest

\section{References}

1 George OA, Adenipekun EO, Fasogbon SA, Oparanozie JA. Antimicrobial Activities of Chrysophyllum albidum Leaves, Fruits and Seeds. Am. J. Biomed. Sci. 2018; 10(1): 28-44; DOI: 10.5099/aj180100028

2 Yakubu MT, Akanji MA, Oladiji AT. Aphrodisiac potentials of the aqueous extract of Fadogia agrestis (Schweinf. Ex Hiern) stem in male albino rats. Asian J Androl 2005; 7(4): 399-404 DOI: $\quad \underline{10.1111 / \mathrm{j} .1745-}$ 7262.2005.00052.x

3 Iwu MM, Duncan AR, Okunji CO. New antimicrobials of plants origin, Janick, J., Ed.; Perspectives on new crops and new uses, Alexandria. ASHS press. 1999; pp 457-462

4 Mahmoodi M, Eghbali H, Hosseini zijoud SM, Pourrashidi A, Mohamadi AR, Borhani M, Hassanshahi G, Rezaeian M. Study of the Effects of Walnut Leaf on Some Blood Biochemical Parameters in Hypercholesterolemic Rats. Biochem and Anal Biochem. 2011; 1(1):103. DOI: $\underline{10.4172 / 2161-1009.1000103}$

5 Dasofunjo OK,Nwodo OF, John JT, Ukpanukpong RU, Ugwu MN, Ayo VI. Phytochemical screening and effect of ethanolic leaf extract of Piliostigma thonningii on lipid profile of male albino rats, J. Nat.

Prod. Plant Resour., 2013; 3 (2):1-4

6 Afzan A, Abdullah NR, Halim SZ, Rashid BA, Semail RH, Abdullah N, Jantan I, Muhammad $\mathrm{H}$, Ismail Z. Repeated dose 28-days oral toxicity study of Carica papaya L. leaf extract in Sprague Dawley rats. Molecules 2012; 17(4): 4326-4342 DOI: $\underline{10.3390 / \text { molecules } 17044326}$

7 Imaga NO, Gbenle GO, Okochi VI, Akanbi SO, Edeoghon SO, Oigbochie V, Kehinde MO, Bamiro SB. Antisickling property of Carica 
papaya leaf extract. Afr. J. Biochem. Res. 2019; 3(4), 102-106. DOI: 10.5897/AJBR .9000034

8 Adeneye AA, Olagunju JA, Banjo AA, Abdul SF, Sanusi OA, Sanni OO, Osarodion BA, Shonoiki OE. The Aqueous Seed Extract of Carica papaya Linn. Prevents Carbon Tetrachloride Induced Hepatotoxicity in Rats. Int. J. of Applied Res. In Natural Products. 2009; 2(2): 19-32. DOI: 10.1.1.895.5985

9 Ayoola PB, Adeyeye A. Phytochemical and Nutrient Evaluation of Carica papaya (Pawpaw) leaves. Inter J Recent Res Applied Studies. 2010; 5(3): 23-24.

10 Ayotunde EO, Offem BO, Bekeh AF. Toxicity of Carica papaya Linn: Haematological and Piscicidal Effect on Adult Catfish (Clariasgariepinus). Journal of Fisheries and Aquatic Sci. 2011; 6: 291-308. DOI: 10.3923/jfas.2011.291.308

11 Falade OA,Odubanjo OV. Consumption of thermally oxidized palm oil diets alters biochemical indices in rats. Beni-Suef University Journal of Basic and Applied Sci. $2015 . \quad 4(2)$ : 150-156. DOI: 10.1016/j.bjbas.2015.05.009

12 May CY, Nesaretnam K. Research advancements in palm oil nutrition. Eur $\boldsymbol{J}$ Lipid Sci Technol 2014; 116(10): 1301-1315 DOI: $10.1002 /$ ejlt.201400076

13 Ebong PE, Owu DU, Isong EU. Influence of palm oil (Elaesis guineensis) on health. Plant Foods Hum Nutr. 1999; 53: 209 -222. DOI: 10.1023/A: 1008089715153

14 Isong EU, Essien EU, Eka OU, Umoh IB. Sexand organ-specific toxicity in normal and malnourished rats fed thermoxidized palm oil. Food Chem Toxicol 2000; 38(11): 997-1004 DOI: $10.1016 / \mathrm{s} 0278-6915(00) 00102-2$

15 Mukherjee S, Mitra A. Health Effects of Palm Oil. J Hum Ecol. 2009; 26(3): 197-203. DOI: 10.1080/09709274.2009.11906182

16 Inneh C, Uhonmoibhi S, Oghenakhogie M. Effect of aqueous seed extract of Carica papaya on Lipid profile and Anti-Atherogenic index of Wistar Rats following cholesterol administration. FASEB. 2019: 343(1). DOI: 10.1096/fasebj.2019.33.1 supplement.522.10

17 Thomas L. Clinical Laboratory Diagnostics; Frankfurt: TH-Books Verlagsgesellschaft; 1998.

18 Turner LB. A meta-analysis of fat intake, reproduction, and breast cancer risk: an evolutionary perspective. Am J Hum Biol 2011; 23(5): 601-608 DOI: 10.1002/ajhb.21176

19 Alli YR, Adanlawo IG. Tissue Lipid Profile of Rats Administered Saponin extract from the Root of Bitter Kola. Adv Biochem. 2003; 1(1): 1-4. DOI: $10.11648 /$ j.ab.20130101.11

20 Mesembe OE, Ibanga I, Osim EE. The Effects of Fresh and Thermoxidized Palm Oil Diets on Some Haematological Indices in the Rat. Niger J Physiol Sci. 2005: 19(1) DOI: 10.4314/njps.v19i1.32641

21 Mohamed Sadek K. Antioxidant and immunostimulant effect of carica papaya linn. Aqueous extract in acrylamide intoxicated rats. Acta Inform Med 2012; 20(3): 180-185 DOI: $\underline{10.5455 / \mathrm{aim} .2012 .20 .180-185}$ 